\title{
Función de los consultorios jurídicos en el posconflicto
}

\author{
[Artículos]
}

\author{
Gloria Inés Romero-Rodríguez ${ }^{*}$
}

Recibido: 10 de octubre de 2020

Aprobado: 30 de noviembre de 2020

Citar como:

Romero Rodríguez, G. I. (2021). Función de los consultorios jurídicos en el posconflicto. Revista IUSTA, (54). https://doi.org/10.15332/25005286.6555

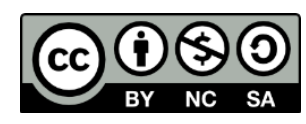

\section{Resumen}

Este artículo es un avance de una investigación sobre la situación de las víctimas del conflicto armado en el posconflicto luego de la firma de los Acuerdos de Paz entre el Estado colombiano y las Fuerzas Armadas Revolucionarias de Colombia - Ejército del Pueblo (FARC-EP), en la que se propone la firma de un convenio entre la Defensoría del Pueblo y la Jurisdicción Especial para la Paz (JEP) como mecanismos para agilizar la capacidad de respuesta de esta corporación. Este convenio apuntaría a que los estudiantes de derecho adscritos a los consultorios jurídicos de las Facultades de Derecho colombianas se puedan vincular al Sistema

\footnotetext{
* Magíster en Intervención Social en las Sociedades del Conocimiento por la Universidad Internacional de La Rioja, España; especialista en Informática Educativa por la Universidad Libre; especialista en Pedagogía para la Docencia Universitaria por la Fundación Universitaria del Área Andina; Abogada por la Corporación Universitaria Republicana; Licenciada en Ciencias Sociales por la Universidad Distrital Francisco José de Caldas. Docente y abogada litigante. Directora del Consultorio Jurídico de la ONG Fundación Margherita Lotti (Colombia). Correo electrónico: gloriaromero20005@hotmail.com. ORCID: http://orcid.org/0000-0002-4851-6394
} 
Autónomo de Asesoría y Defensa Gratuita (SAAD), como mecanismo para lograr una atención acertada a las víctimas del conflicto armado de escasos recursos, entendiendo que la consolidación de lo propuesto en el tratado firmado por las partes exige que las personas de escasos recursos víctimas del conflicto armado tengan un trato prevalente que les asegure una atención integral, si se desea alcanzar la construcción de un nuevo modelo de sociedad. Para ello, se parte de la hipótesis de que la atención de los consultorios jurídicos a las víctimas del conflicto armado de escasos recursos mejoraría la implementación del SAAD reglamentado en el Decreto 1166 del 11 de julio de 2018.

Palabras clave: consultorio jurídico, Defensoría del Pueblo, Facultades de Derecho, Sistema Autónomo de Asesoría y Defensa Gratuita (SAAD), víctimas del conflicto armado.

\section{Role of legal clinics in the post-conflict}

\section{Abstract}

This article is an advance of a research on the situation of the victims of the armed conflict in the post-conflict after the signing of the Peace Agreement between the Colombian State and the Revolutionary Armed Forces of Colombia (Fuerzas Armadas Revolucionarias de Colombia Ejército del Pueblo) (FARC-EP) which proposes the signing of an agreement between the Ombudsman's Office and the Special Jurisdiction for Peace (JEP) as mechanisms to streamline the response capacity of this corporation. This agreement would allow law students assigned to legal clinics of Colombian law schools to join the Autonomous System of Free Counseling and Defense ( $S A A D)$, as a mechanism to achieve an adequate service for low-income victims of the armed conflict, understanding that the consolidation of what is proposed in the treaty signed by the parties requires that low-income victims of the armed conflict have a preferential treatment that ensures them a comprehensive care, if the construction of a new model of society is to be achieved. To 
this end, it is assumed that the service of legal clinics to low-income victims of the armed conflict would improve the implementation of the $S A A D$ regulated in Decree 1166 of July 11, 2018.

Keywords: legal clinic, Ombudsman's Office, law schools, Autonomous System of Free Counseling and Defense ( $S A A D)$, victims of the armed conflict.

\section{Função dos consultórios jurídicos no pós-conflito}

\section{Resumo}

Este artigo é um avanço de uma pesquisa sobre a situação das vítimas do conflito armado no pós-conflito após a assinatura dos Acordos de Paz entre o Estado colombiano e as Forças Armadas Revolucionárias da Colômbia-Exército do Povo (Farc-EP), na qual se propõe a assinatura de um convênio entre a Defensoria do Povo e a Justiça Especial para a Paz (JEP) como mecanismo para agilizar a capacidade de resposta dessa cooperação. Esse convênio apontaria a que os estudantes de Direito dos consultórios jurídicos das faculdades de Direito colombianas possam se vincular também ao Sistema de Assessoria e Defesa Gratuita (Saad), como mecanismo para oferecer um atendimento efetivo às vítimas do conflito armado de baixos recursos, entendendo que a consolidação do proposto no tratado firmado pelas partes exige que as pessoas de baixos recursos vítimas do conflito aramado tenham um tratamento prevalente que lhes garanta atenção integral, se se desejar atingir a construção de um novo modelo de sociedade. Para isso, parte-se da hipótese de que o atendimento dos consultórios jurídicos às vítimas do conflito armado de baixos recursos melhoraria a implementação do Saad regulamentado no Decreto 1.166 del 11 de julho de 2018.

Palavras-chave: consultório jurídico, Defensoria do Povo, faculdades de Direito, Sistema Autônomo de Assessoria e Defesa Gratuita (Saad), vítimas do conflito armado. 


\section{Introducción}

En este escrito, se enfatiza la atención a las víctimas en el marco del posconflicto entre el Estado colombiano y la guerrilla de las Fuerzas Armadas Revolucionarias de Colombia - Ejército del Pueblo (FARC-EP). El posconflicto que actualmente está viviendo el país es un momento histórico de gran importancia, ya que es el fin de un conflicto que duró más de cinco décadas, se presentó en todo el territorio nacional e impactó a todas las clases y sectores sociales.

El fin del conflicto armado interno no solo significa un paso positivo y notorio de la sociedad colombiana, sino que exige un replanteamiento de la política criminal, del derecho penal y, en general, del rol de los abogados dedicados a la defensa de la libertad o de las víctimas dejadas por tal confrontación social. Esta renovación necesariamente debe impactar a los consultorios jurídicos de las facultades de derecho de las universidades colombianas que, desde su creación, respondieron a la urgencia de revitalizar los programas de derecho que, como dicen Recalde et ál. (2017), "no habían sido reformados desde la era republicana y privilegiaban y entre otras cosas, una educación memorística, enciclopédica, acrítica y desconectada de la realidad social" (p. 12).

El papel del abogado en el posconflicto exige un replanteamiento de la profesión en la que se reflexione sobre nuevos aspectos como "paz, reconciliación, reinserción a la vida civil, restitución, acceso a la justicia, etc., y nada de eso se logra con el sistema tradicional" (Arboleda, 2017, s. p.), rol que las facultades de derecho no van a poder enfrentar solo con el estudio de los códigos formulados hace unos cien años. Tampoco se va a resolver únicamente con el estudio de los clásicos dogmáticos en asuntos penales, ni de reflexiones hechas sobre la justicia restaurativa en otros países que, en todo caso, se deben hacer, pero teniendo presente que el 
ejercicio de los derechos ciudadanos en una sociedad en paz es diferente al que se realiza en una sociedad en confrontación (Morales y Daza, 2016). Como lo afirman Bonilla et ál. (2016): "Es imperante una ciudadanía emergente en Colombia que comprometa al Estado a conceder los espacios y las disposiciones necesarias para generar los cambios y transformaciones esenciales para el éxito del posconflicto" (p. 51).

El objetivo de este artículo es demostrar que los consultorios jurídicos en el posconflicto colombiano pueden vincularse al Sistema Autónomo de Asesoría y Defensa Gratuita (SAAD). Esto les daría la ventaja de formar a las futuras promociones de abogados en un nuevo ejercicio de litigio acorde al modelo de justicia transicional pactado para lograr la paz en el país, tomando como punto central de sus esfuerzos la defensa de los derechos de las víctimas del conflicto armado de escasos recursos, especialmente de las que más problemas presentan al momento de su reconocimiento, como son las que generan las acciones criminales de las bandas criminales (Bacrim).

En la Sentencia C-253A del 2012, "la Corte reconoce que existe dicha dificultad fáctica y, por ende, hay casos en los cuales las víctimas de las Bacrim podrían ser beneficiarias de la reparación” (López, 2015, p. 22), víctimas que, en virtud de la Sentencia T-834/14 de la Corte Constitucional, son contadas por la Unidad de Víctimas, pero que su atención y reparación todavía tiene grandes vacíos, toda vez que esta clase de victimarios no hacen parte del proceso de paz que vive Colombia, pero sí son agentes cada vez más amenazantes de la estabilidad social.

En ese marco, cobra importancia la definición o nombramiento de estos nuevos grupos, lo cual no es problema menor, ya que de la forma como se le catalogue se define, entre otras, las maneras e intensidades para enfrentarlos, además de las características para su tratamiento político en el contexto nacional e internacional. (Pacheco, 2019, p. 1)

Revista IUSTA ISSN: 1900-0448 | e-ISSN: 2500-5286 | DOI: https://doi.org/10.15332/25005286 N. ${ }^{\circ} 54$ | enero-junio de 2021 
La universidad, a partir de la interacción con las víctimas, está llamada a ir construyendo un modelo propio de cómo debe ser el procedimiento para su atención e incorporación a la sociedad colombiana de manera integral, respetando su identidad personal y grupal o comunitaria, proceso en el que los consultorios jurídicos deben participar en la formación de un nuevo número de abogados capaces de responder a las necesidades de la sociedad. "El profesional del Derecho de hoy ya no debe partir de entender los libros para entender su entorno; debe hacerlo para hacer propuestas creativas para la sociedad" (Arboleda, 2017, s. p.).

La orientación propuesta en este artículo les brinda a los consultorios jurídicos de las facultades de derecho colombianas la posibilidad de abrirse un camino idóneo de formación del ejercicio profesional mediante la realización de un aporte concreto a la consolidación del posconflicto, independientemente de que los estudiantes de consultorio jurídico puedan actuar en la Jurisdicción Especial para la Paz (JEP), ya que, cuando se iniciaron los consultorios jurídicos en universidades, como en la de Antioquia - en la que comenzaron-, los Andes, Santo Tomás, Externado y Cauca, los consultorios jurídicos estaban destinados a la formación profesional a través de actividades didácticas y no a su participación directa en el sistema judicial. Fruto de la existencia de estos espacios en dichas universidades, "ampliaron sus actividades hacia la pedagogía en derechos mediante actividades didácticas organizadas con comunidades vulnerables y su participación en programas de televisión educativa" (Recalde et ál., 2016, p. 37).

Dado que una de las razones de la existencia de los consultorios jurídicos es la atención de las personas de escasos recursos, con el ánimo de que puedan reclamar y materializar sus derechos mediante la asesoría gratuita a personas que de lo contrario no podrían recurrir al sistema judicial, la oportunidad de atender a las víctimas del conflicto armado es única y de 
gran poder formativo y de proyección profesional, entendiendo que en los consultorios jurídicos los estudiantes "aprenden haciendo, a través de la asesoría y representación jurídica de personas vulnerables en su comunidad, no únicamente a partir de la discusión de artículos académicos o normas jurídicas bajo la dirección de un profesor" (Recalde et ál., 2016, p. 11).

La propuesta de que los consultorios jurídicos colaboren con el SAAD en la atención de las víctimas de escasos recursos está en concordancia con el artículo 1. ${ }^{\circ}$ del Decreto 196 de 1971, que establece lo siguiente: "La abogacía tiene como función social la de colaborar con las autoridades en la conservación y perfeccionamiento del orden jurídico del país, y en la realización de una recta y cumplida administración de justicia”.

Para ello, se parte en esta investigación de la hipótesis de que la atención de los consultorios jurídicos a las víctimas del conflicto armado de escasos recursos mejoraría la implementación del SAAD reglamentado en el Decreto 1166 del 11 de julio de 2018. Tal afirmación se apoya en un análisis documental comparativo de tipo cualitativo, en el que se toma como referencia la Ley 1957 de 2019, con los datos sobre la atención de las víctimas y su reparación, que han venido recolectando e informando las diversas instituciones, organismos y sectores especializados en el tema. Después de esta introducción, este artículo se compone de un apartado dedicado a un análisis somero de la legislación anteriormente mencionada y la conexa a ella, mostrando cómo son las víctimas, su protección y reparación el centro de las mismas; después, se exponen los problemas y avances más significativos de la atención de las víctimas del conflicto armado en Colombia, enumerando los principales alcances, falencias, carencias y retos que se vienen presentando; finalmente, se ofrece un 
diagnóstico somero de los consultorios jurídicos de las universidades del país y cómo es posible vincularlos al SAAD.

\section{Un acercamiento a las víctimas a través de la Ley 1957 de 2019}

Desde el punto de vista normativo, se ha buscado que la protección, la reparación y el restablecimiento de los derechos de las víctimas sean el centro del proceso de paz con las FARC, lo cual quedó plasmado en la Ley 1957 de 2019 -Estatutaria de la Administración de Justicia en la Jurisdicción Especial para la Paz-, al principio de su articulado, de la siguiente manera:

Artículo 1. ${ }^{\circ}$. Garantía de los derechos de las víctimas. El Estado tiene el deber jurídico de garantizar y atender los derechos de las víctimas y con la misma intensidad, la obligación de prevenir nuevos hechos de violencia y alcanzar la paz en un conflicto armado por los medios que estén a su alcance.

Más adelante, en el artículo 15, la misma Ley enumera los derechos de las víctimas, resaltando cómo "gozan de los derechos a la verdad, justicia, reparación, y garantías de no repetición”. Para tal fin, en la JEP las víctimas, a través de su representante, tienen derecho a su reconocimiento dentro del proceso judicial, quienes pueden aportar pruebas e interponer recursos; recibir asesoría, orientación y representación judicial a través del sistema autónomo de asesoría y defensa de tal jurisdicción; contar con acompañamiento psicológico y jurídico en sus procedimientos; deben ser tratadas con justicia, dignidad y respeto, y recibir información del avance de la investigación y del proceso, así como de cuándo se llevarán a cabo las distintas audiencias para que puedan intervenir en ellas (Galán, 2017). 
De igual forma, en los casos en que haya reconocimiento de verdad y responsabilidad, las diferentes salas están facultadas a llevar a cabo audiencias públicas en presencia de víctimas individuales o colectivas afectadas, sin perjuicio de que dicho reconocimiento se realice por escrito. En los casos de reconocimiento escrito, deberá entregárseles copia de este a las víctimas directas y se les dará la debida publicidad conforme a las normas de procedimiento propias de tal jurisdicción (Guarín y Aldana, 2016). Además, en el mismo artículo 15, en el parágrafo primero, se concreta cuáles son las víctimas que se reconocen como tales para la JEP, aclarando lo siguiente:

Servirá como medio de prueba de la condición de víctima, el reconocimiento que de ella se hubiese hecho administrativamente, su inclusión en bases de datos, y el otorgamiento de asilo o refugio por una nación extranjera por motivos relacionados directamente con el conflicto armado. (Ley 1957 de 2019, art. 15, Colom.)

Por otra parte, en el segundo parágrafo se indica cómo en la ley procedimental se reglamentará lo relacionado con el número de representantes que podrán intervenir en cada caso. Al momento de la sanción presidencial de la Ley 1957 de 2019, la JEP manifestó que con ella completaba los criterios para lograr ejercer "la acción penal respecto a quienes tuvieron participación determinante en los hechos más graves y representativos del conflicto armado" ("Lo que trae la Ley Estatuaria...", 2019, párr. 26). El articulado de esta normativa está compuesto de 159 artículos, en lo que se establece la competencia material de la JEP (artículo 62), donde se indica cómo conocerá todos los delitos cometidos por causa, con ocasión o en relación directa con el conflicto armado por combatientes de los grupos armados al margen de la ley o agentes del Estado, limitando su actuación frente a los primeros, a quienes hayan suscrito el Acuerdo 
Final de Paz, los cuales serán retornados a la justicia ordinaria en caso de disidencia y deserción (Humbarita, 2015).

En lo que respecta a los agentes del Estado no integrantes de la fuerza pública, solo conocerá a quienes hayan manifestado voluntariamente su intención de someterse, bajo el entendido de que la competencia temporal de la JEP se ejercerá en los términos establecidos en el artículo transitorio 5. ${ }^{\circ}$ del Acto Legislativo 01 del 2017. ("Lo que trae la Ley Estatuaria...", 2019). En lo que respecta al SAAD, la Ley 1957 de 2019, en el artículo 115, exige que los defensores y organizaciones seleccionados para este sistema:

Deberán inscribirse en el Registro de Abogados del Sistema Autónomo de Asesoría y Defensa que para tal efecto cree y administre la Secretaría Ejecutiva de la JEP, sin perjuicio de que este sistema se articule con el administrado por la Defensoría del Pueblo. (Ley 1957 de 2019, art. 115, Colom.)

Como es sabido, los estudiantes de los dos últimos años de las facultades de derecho se vinculan al sistema de la Defensoría como lo establece la Ley 583 de 2000, que instituye en el artículo primero lo siguiente: "Las facultades de derecho oficialmente reconocidas organizarán, con los alumnos de los dos (2) últimos años lectivos, consultorios jurídicos cuyo funcionamiento requerirá aprobación del respectivo Tribunal Superior de Distrito Judicial, a solicitud de la facultad interesada”.

De la misma manera, la Ley 583 del 2000 en su primer artículo exige que los consultorios jurídicos funcionen "bajo la dirección de profesores designados al efecto o de los abogados de pobres, a elección de la facultad, y deberán actuar en coordinación con éstos en los lugares en que este servicio se establezca" (art. 1, Colom.), para lo cual deben verificar la capacidad económica de sus usuarios. Es decir, para que una persona pueda acceder a los consultorios jurídicos de las facultades de derecho es 
indispensable demostrar su incapacidad económica para poder pagar un abogado. "Los estudiantes adscritos a los consultorios jurídicos de las facultades de derecho son abogados de pobres y como tales deberán verificar la capacidad económica de los usuarios" (Ley 583 de 2000, Colom.).

Además, para ser usuario del SAAD, se necesita del reconocimiento como víctima por el Estado y demostrarse que no se cuenta con los recursos suficientes para costear la representación de un abogado. En la página oficial de la JEP, al explicar cómo funciona el SAAD, se aclara que este se ofrece de manera gratuita, con abogados especializados en el tema y que la Secretaría Ejecutiva de la JEP es la encargada de administrarlo.

Básicamente, el objetivo del SAAD es el siguiente:

Asegurar el ejercicio del derecho de defensa de las personas que se sometan ante la JEP, y el derecho a la asesoría jurídica de las víctimas, cuando unos u otros carezcan de recursos económicos suficientes, sin que esto signifique que no puedan acudir a los sistemas de defensa pública dispuestos en el ordenamiento jurídico colombiano ya existentes o defensores de confianza. (JEP, 2019, párr. 6)

Así las cosas, a través de un convenio entre la JEP y la Defensoría del Pueblo, los consultorios jurídicos podrían participar en la JEP, con lo cual es posible mejorar y aumentar la capacidad de atención a las víctimas con menos capacidad de contratar un togado. El mismo artículo 115 de la Ley 1957 de 2019 le permite a la Secretaría Ejecutiva de la JEP entablar convenios interadministrativos con la Defensoría del Pueblo para la gestión del SAAD y mejorar la eficiencia de "la prestación del servicio de defensoría pública y de asesoría y representación de los intereses de las víctimas" que atienda la JEP. Asimismo, en el artículo 115, a las víctimas se les da la posibilidad de acudir al SAAD o a los sistemas de defensa pública 
dispuestos en el ordenamiento jurídico colombiano o a los defensores de confianza, con el ánimo de que puedan acceder con similares estándares de calidad, pertinencia y oportunidad. En ese mismo artículo, se llama al Estado a establecer los necesarios convenios de financiación con las organizaciones de derechos humanos o de víctimas designadas "con el fin de que todos los destinatarios de esta ley disfruten de un sistema de defensa con la misma idoneidad" (Ley 1957 de 2019, art. 115, Colom.). Esto está en concordancia con lo dispuesto en el Decreto Presidencial 1166 del 11 de julio del 2018, que en el artículo 2.2.5·7.1.5 indica que el Sistema Autónomo de Asesoría y Defensa Gratuita "está destinado única y exclusivamente a la asistencia, asesoría y defensa de los beneficiarios del SAAD”, con el fin de responder al deber de garantizar los derechos de las víctimas.

La implementación normativa del Acuerdo Final, en especial del Sistema Integral de Verdad, Justicia, Reparación y No Repetición (sivjrnr), ha tenido como principal desafío hacer realidad un principio mencionado de forma constante en el marco de las negociaciones: 'Las víctimas están en el centro del acuerdo'. Este principio es relevante porque resume la razón de ser de las instancias y las medidas que componen el sivjrnr, y responde a las expectativas de las víctimas en relación con el proceso de transformación que conlleva el cumplimiento del Acuerdo Final. (Leyke et ál., 2018, p. 4)

Aquí hay que resaltar que la sociedad civil juega un gran protagonismo en la confirmación del proceso, mediante "la creación de mecanismos para que la ciudadanía y la administración, puedan observar la ejecución y resultados de los acuerdos para el fin del conflicto o para la paz" (Castellanos, 2018, p. 18), entendiendo que el control de la ciudadanía va más allá de las instancias de control público, que están amparadas por lo que se exponga en los medios de comunicación, por la credibilidad que 
alcance este acuerdo de paz en la sociedad en general y por la aceptación que los fallos que la JEP emita en la ciudadanía y las organizaciones que en la sociedad colombiana tienen presencia.

\section{Las víctimas del conflicto armado en Colombia}

En este apartado se exponen los problemas y avances más significativos de la atención de las víctimas del conflicto armado en el país, enumerando algunos de los alcances, falencias, carencias y retos que se vienen presentando a pesar del esfuerzo normativo y legislativo para poner su atención en el centro de los esfuerzos gubernamentales. Partiendo del contexto que se desprende de la longevidad del conflicto y su presencia a nivel nacional, que dejó un alto número de víctimas directas, dificultades en la delimitación de quiénes son y en el que toda la sociedad colombiana ha sufrido heridas, es urgente también crear estrategias para su atención. Así fue establecido en el Acuerdo final para la terminación del conflicto y la construcción de una paz estable y duradera (Colombia, 2016). En el Acuerdo, el Estado colombiano se comprometió a "generar medidas alternas que busquen reparar el daño hecho en la sociedad en general en el marco del conflicto armado" (Castellanos, 2018, p. 3). En términos generales, se puede decir que los problemas de las víctimas en Colombia se centran en los tiempos en su atención y reparación, los bajos montos que se les reconoce y las pocas o nulas políticas locales que se están generando para su atención.

Cuatro años después de haber entrado en vigencia la Ley de Víctimas, tres dificultades ensombrecen sus logros: los titubeos en la aceptación de las víctimas de las bandas criminales como parte del universo de personas a reparar; el abismo que hay entre el dinero que se entrega por reparación administrativa y los montos que contemplan los fallos 
judiciales; y el temor de que los nuevos alcaldes y gobernadores le saquen el cuerpo al tema. (Verdadabierta.com, 2015, p. 4)

El problema de las víctimas de las bandas criminales (Bacrim) es que, si bien ellas deben recibir los mismos beneficios de las víctimas de las FARC o los paramilitares, tal como lo estableció la Corte Constitucional en la Sentencia T-834/14, en la que se deja claro que en Colombia: "Toda persona que haya sido objeto de desplazamiento forzado tiene el derecho a ser registrada como tal de forma individual o con su núcleo familiar" (CC, 2014, Colom.), el Registro Único de Víctimas (RUV) debe garantizar los derechos de quienes se encuentran en esa situación. Si bien en esa sentencia se ordena que la accionante, una mujer que fue abusada sexualmente por miembros de Bacrim, fuera incluida en el programa establecido por la Ley de Víctimas, es decir, que se le diera tratamiento de víctima del conflicto armado a una persona afectada por un grupo ilegal distinto de las FARC y las AUC, el debate es que esta clase de agrupaciones ilegales no han recibido aceptación por parte del Estado colombiano para un acuerdo de paz ("Corte ordena reparar...", 2015). En la Sentencia T834/14 se le llama la atención al Gobierno para que tome "medidas para la prevención del desplazamiento forzado, atención, protección, consolidación y estabilización socioeconómica de los desplazados internos por la violencia, y se le impuso al Estado la obligación de formular políticas para lograr esos objetivos” (“Corte ordena reparar...”, 2015, párr. 8).

La Fundación Ideas para la Paz (FIP), el día 10 abril de 2018, a menos de dos años de la firma del Acuerdo de Paz entre el Gobierno y las FARC, calculó unos 1200 disidentes según las fuentes oficiales, que según otras fuentes podían llegar a 1500. En su investigación de más de un año, ofrece un análisis documentado con cifras, mapas y datos para conocer más sobre la problemática de esta clase de grupos y personas que han continuado creciendo hasta el momento actual. Según la FIP, "las disidencias no 
cuentan con alta capacidad armada, pero sus acciones tienen gran impacto humanitario y parecen utilizar el modus operandi que tenían las FARC" (Álvarez et ál., 2018, p. 1).

Las disidencias de las FARC que ensombrecen la paz en el país son exmiembros de las FARC que no entregaron sus armas. Su presencia obedece a las divisiones debidas a la falta de interés de algunos integrantes de esta clase de grupos de incorporarse nuevamente a la vida civil y a renunciar a sus prácticas. Su existencia es un fenómeno recurrente en el ámbito internacional en esta clase de tratados: "En el caso de las FARC se destacan la degradación interna de tipo criminal de varias estructuras; la proyección hacia el postconflicto de comportamientos y lógicas de violencia de corte político y militar" (Álvarez et ál., 2018, p. 1) La evidencia muestra que algunas de estas disidencias tienen como líderes a "mandos medios con experiencia y amplia y reconocida trayectoria en la guerrilla por su trabajo político, social, militar y financiero" (Álvarez et ál., 2018, p. 1). Además de las disidencias, en las Bacrim hay grupos armados ilegales al servicio del narcotráfico y de delincuencia organizada, tales como la Oficina de Envigado o el Clan Úsuga (gaitanistas), de los cuales se calculaban que, solamente en el departamento de Antioquia, había unos 13500 en el 2017, según la Corporación para la Paz y el Desarrollo Social (Kapkin, 2017).

En el 2012, cuando comenzaron las negociaciones entre las FARC y el Gobierno - que concluirían en el 2016-, la violencia asociada al conflicto disminuyó hasta fines del 2017, cuando se recrudecieron debido a las disputas dentro del territorio nacional por parte de las organizaciones criminales y grupos armados ilegales. Aunque en el 2018 continuaron su crecimiento, en el 2019 volvieron a caer, debido a que se calmó el conflicto por acuerdos logrados entre las organizaciones criminales (Pares, Fundación Paz y Reconciliación, 2019). Por eso, es posible concluir que el 
número de víctimas por el conflicto armado sigue en crecimiento, a pesar de la firma de la paz con la guerrilla de las FARC y su desmovilización definitiva: "Ramón Rodríguez, director de la Unidad de Víctimas, contó que en el registro nacional en este momento hay más de 8.9 millones de víctimas y advirtió que todavía se están recibiendo solicitudes" (“Indemnizar a todas las víctimas...”, 2020, párr. 1).

En este contexto, al comenzar el 2020, el número de víctimas registradas en la Red Nacional de Información era de 8944137 (Red Nacional de Información [RNI], 2020, p. 1), pero todavía hay en el país grandes controversias al momento de su delimitación conceptual, por lo que no ha sido claro el modelo con el que se están contabilizando, así como los mecanismos idóneos para repararlas o el diseño de políticas locales para su atención, tal como sucede con los menores de edad víctimas de reclutamiento ilícito.

La Ley 1448 de 2011 no considera víctima a quien, habiendo sido sujeto de reclutamiento forzado por parte de un grupo armado ilegal, se desmovilice siendo mayor de edad después de la firma del acuerdo de paz, mientras que a quien tiene las mismas características pero se desmoviliza siendo aún menor le reconoce la calidad de víctima y lo hace acreedor a la reparación contenida en la propia Ley 1448. (Aguirre, 2019, p. 2)

Otro problema es que el Estado colombiano no les reconoce a las Bacrim ningún carácter insurgente, ideológico o político, por lo que, si bien gracias a la Sentencia T-834/14, a las personas afectadas por estas bandas criminales se les pueda incorporar en el Registro Nacional de Víctimas, la Ley 1448 establece que las Bacrim no cometen infracciones al Derecho Internacional Humanitario, por lo que en sentido estricto no serían víctimas las personas o grupos afectadas por estas bandas ("Corte ordena reparar...”, 2015). La Corte Constitucional, en la síntesis de la decisión de 
la Sentencia T-834/14, aclara que en la expresión "con ocasión del conflicto armado", la definición operativa de "víctima" del artículo $3 \cdot{ }^{\circ}$ de la Ley 1448 de 2011, se inserta al universo de víctimas beneficiarias de la ley, de manera constitucional y compatible con el principio de igualdad:

Como quiera que quienes lleguen a ser consideradas como tales por hechos ilícitos ajenos al contexto del conflicto armado, aun cuando no sean beneficiarios de la Ley 1448 de 2011, pueden acudir a la totalidad de las herramientas y procedimientos ordinarios de defensa y garantía de sus derechos provistos por el Estado colombiano y su sistema jurídico. (CC, 2014, p. 106)

Para el alto tribunal, la expresión "con ocasión del conflicto armado" cobija situaciones ocurridas en el contexto del conflicto armado en concordancia con la ratio decidendi de la Sentencia C-253A de 2012 "en el sentido de declarar que la expresión 'con ocasión de' alude a 'una relación cercana y suficiente con el desarrollo del conflicto armado"” (CC, 2014, p 106). La Sentencia T-834 de 2014 se apoya en una noción amplia de "conflicto armado" que ha sido reconocido en numerosos pronunciamientos jurisprudenciales, en los cuales se incluye toda la complejidad y evolución fáctica e histórica del conflicto armado interno colombiano: "estos criterios fueron tenidos en cuenta por el Legislador al expedir la Ley 1448 de 2011 y constituyen criterios interpretativos obligatorios para los operadores jurídicos encargados de dar aplicación concreta a la Ley 1448 de 2011” (CC, 2014, p. 107).

Así las cosas, para la Corte Constitucional, las víctimas de desplazamiento forzado son todos aquellos afectados por delitos contra los derechos humanos o el derecho internacional humanitario:

[...] como pueden ser las que actualmente perpetran las denominadas bandas criminales, los desmovilizados de grupos armados que en lugar 
de reintegrarse a la vida civil hubieren reincidido en su accionar delictivo e incluso los afectados por desastres de la naturaleza generados dentro del conflicto, como sería la voladura de una represa. (CC, Sentencia C280/13, Colom.)

En el país, de las 8944137 de víctimas solo 7181215 son sujeto de reparación para obtener una indemnización administrativa (RNI, 2020, p. 1) por lo que se calcula que solo al $13 \%$ del total, es decir, unas 957000 , se podrán reparar hasta junio del 2021. En el momento actual, se calcula que "solo un $2 \%$ de las víctimas del conflicto armado inscritas en el Programa de Reparación Colectiva han podido finalizar sus procesos" (“Solo el 2\% de las víctimas...”, 2020, párr. 2). Ante este poco porcentaje que se puede cubrir con el límite temporal fijado en el artículo 208 de la Ley 1448 de 2011, y teniendo en cuenta que al otro más de $85 \%$ que no alcanzaría la indemnización se le vulnerarían sus derechos, la Corte Constitucional decidió que ese plazo fijado debe extenderse, para lo cual ha exhortado al Congreso para que expida una nueva regulación que garantice adecuadamente los derechos de las víctimas, "de no hacerlo antes de 2021, «se entenderá que la Ley 1448 de 2011, así como los decretos 4633, 4634, 4635 de 2011 tendrán vigencia hasta el 7 de agosto de 2030»" (“Corte Constitucional amplió...”, 2019).

La Ley de Víctimas y Restitución de Tierras fue el punto inicial del Proceso de Paz con el grupo guerrillero de las FARC, que culminó en el Acuerdo de Paz, y que comprende un conjunto de políticas públicas de reparación administrativa y restitución de tierras; de ella se desprende el Sistema de Verdad, Justicia, Reparación y No Repetición, por lo que la expiración de su vigencia dejaría a las víctimas

[...] sin ningún mecanismo propio que garantizara las medidas de asistencia, acceso a educación, salud, generación de ingresos, seguridad alimentaria, vivienda y reunificación familiar, en los cuales ha insistido 
persistentemente la Corte Constitucional en la sentencia T-25 de 2004 y en los autos de seguimiento a la misma. (CC, Sentencia C-588/19, Colom., p. 2)

Además, sin unas políticas públicas más amplias sobre la atención de las víctimas, los elevados niveles de pobreza y marginalidad que sufren hacen que la reparación ofrecida por el Estado, por sí sola, tenga poca capacidad de impactar positiva y de manera radical sus condiciones de existencia y realización personal y comunitaria. "Sin el esencial apoyo de una política social complementaria, es imposible que el discurso de la reparación transformadora se convierta en una realidad para las víctimas" (Centro Internacional para la Justicia Transicional [ICTJ], 2015).

Castellanos (2018) propone, a quienes critican la reparación por los "aparentes altos costos" de los programas de atención a las víctimas y los onerosos recursos destinados para el posconflicto, que el mejor argumento que se puede esgrimir es, en resumen, comparar los costos que significaría para el país la continuación del conflicto y sus efectos para la población colombiana.

Hay víctimas que no ocurrieron y de ello ganan todos e incluso el Estado en materia presupuestal. De ello, se puede concluir que el posconflicto, aunque implica una inversión grande, fue una inteligente movida para reducir el gasto en guerra y poder seguir con los cometidos del Estado Social de Derecho para las víctimas y la población en general. (Castellanos, 2018, p. 132)

En las políticas públicas de atención de las víctimas es necesario que ocupe un lugar central el acceso a la justicia y el fortalecimiento del sistema judicial, acordes con la justicia transicional pactada.

Con la Ley 975 de 2005, en el marco del proceso de desarme y desmovilización de las Autodefensas Unidas de Colombia, se 
implementaron medidas para la reparación a las víctimas de los grupos armados al margen de la ley, desde un enfoque de justicia transicional. Este marco político ha marcado considerablemente la política pública en materia de reparación que actualmente se rige por la Ley 1448 de 2011. (Martínez, 2018, p. 11)

Por procesos de paz de otros países se sabe que la justicia transicional es un nuevo campo multidisciplinario en el que se deben incorporar varias figuras como las acciones penales, las comisiones de la verdad, los programas de reparación, la justicia de género, la reforma institucional y las iniciativas de conmemoración, entre otras, todas ellas encaminadas a fortalecer en la sociedad el respeto de los Derechos Humanos.

La justicia transicional es una respuesta a las violaciones sistemáticas o generalizadas a los derechos humanos. Su objetivo es reconocer a las víctimas y promover iniciativas de paz, reconciliación y democracia. La justicia transicional no es una forma especial de justicia, sino una justicia adaptada a sociedades que se transforman a sí mismas después de un período de violación generalizada de los derechos humanos. En algunos casos, estas transformaciones suceden de un momento a otro; en otros, pueden tener lugar después de muchas décadas. (ICTJ, 2009, p. 1)

Cabe resaltar que las políticas públicas en el posconflicto tendientes a fortalecer a la justicia transicional se orientan a la consolidación del modelo democrático, y su mayor objetivo es la obtención de la paz social estable y duradera, en la que, mediante la participación de la sociedad civil, se logre a través de los canales constitucionales confrontar los problemas sociales que existan y ofrecerles a las víctimas el mayor respeto posible.

Estos objetivos tienen más probabilidades de ser alcanzados si se consulta y se logra la participación de las víctimas y de la ciudadanía en general, y si se hace un examen serio de las experiencias de otras 
sociedades. Esto reduce el riesgo de repetir errores, pues rara vez las sociedades en transición pueden darse el lujo de cometerlos. (ICTJ, 2009, p. 2)

Es decir, la justicia transicional es más amplia que la justicia ordinaria, y se espera de ella que se ocupe especialmente de los casos de mayor relevancia y de las principales cabecillas, tomando como base jurídica de su actuación la decisión de la Corte Interamericana de Derechos Humanos, que en el caso Velásquez Rodríguez vs. Honduras de 1988 determinó la obligatoriedad que tienen todos los Estados frente a la defensa de los Derechos Humanos de tomar medidas razonables para prevenir las violaciones de estos en su espacio, de investigar objetivamente y a fondo cuando se cometan violaciones contra estos e imponer las sanciones adecuadas a los responsables de tales acciones, así como garantizar la reparación de las víctimas.

En 1998, la creación de la Corte Penal Internacional fue también significativa, dado que el Estatuto de la Corte consagra obligaciones estatales de importancia vital para la lucha contra la impunidad y el respeto de los derechos de las víctimas. (ICTJ, 2009, p. 2)

En Colombia, uno de los mayores problemas respecto a las respuestas del Estado para el restablecimiento de las víctimas está en el crecimiento del número de estas, debido a las acciones criminales de las Bacrim, ya que estas organizaciones criminales al margen de la ley tienen un gran impacto a nivel local, lo que obliga a que sean los alcaldes, gobernadores, asambleas departamentales y, especialmente, los consejos municipales los que deban tomar acciones específicas sobre cómo atender a las personas según las modalidades de las bandas criminales en cada zona del país. Las Bacrim se caracterizan por la selectividad y poca visibilidad de su modalidad de violencia en relación con el accionar de los grupos 
guerrilleros y paramilitares, pero no significa que sea menos grave, pues sus acciones se caracterizan por estar encaminadas a hacer amenazas, extorsiones y realizar asesinatos selectivos, imponiendo "normas de conducta e intimidación por medio de panfletos. También pueden causar desplazamiento intraurbano, reclutamiento forzado y uso de menores, confinamiento de poblaciones y violencia sexual" (Álvarez, 2017, p. 1). Estos delitos son similares a los que se presentaron durante el conflicto armado entre el Estado y los grupos guerrilleros, pero al carecer las Bacrim de reconocimiento político no es posible llegar a un acuerdo de paz con ellas, como se hizo con los grupos paramilitares o guerrilleros. Para febrero de 2019, en un documento elaborado por el Gobierno nacional, se evidenció que en el país, "hay más de 2400 grupos armados y de delincuencia organizada en Colombia" ("Hay más de 2.400 grupos armados...”, 2019), que básicamente están compuestos por la guerrilla del ELN, las bandas criminales organizadas y las disidencias de las FARC.

Lo alarmante de este documento es que deja en evidencia el ocupamiento de nuevos grupos delincuenciales, o la continuidad de otras organizaciones, en las zonas que fueron abandonadas por las Farc después del acuerdo de paz, con el fin de controlar el narcotráfico y la minería ilegal. (“Hay más de 2.400 grupos armados...”, 2019, párr. 5)

Es decir, la población civil de las zonas más azotadas por el conflicto armado entre el Estado y los grupos guerrilleros sigue siendo objeto de la vulneración de los Derechos Humanos, ahora por cuenta de las Bacrim, sin que la gestión de atención de las víctimas de los lugares que ya fueron despejados de la presencia de los actores del conflicto armado haya sido suficiente, adecuada y apropiada para las urgentes necesidades de las víctimas y del aseguramiento del Proceso de Paz y la consolidación del posconflicto. 


\section{Los consultorios jurídicos y su relación con el SAAD}

Las facultades de derecho tienen la oportunidad de que sus consultorios jurídicos jueguen una función histórica en el posconflicto colombiano a través de convenios con el SAAD, lo que se puede realizar si las universidades hacen convenios con el Sistema Nacional de Defensoría Pública (SNDP) y si la Defensoría del Pueblo pacta tal participación con la Jurisdicción Especial para la Paz (JEP). Tales convenios son posibles dentro de la reglamentación legal de cada una de estas instituciones, y deben estar dirigidos principalmente a la atención de las víctimas de escasos recursos, teniendo como eje de sus labores que los estudiantes de derecho de los últimos semestres ayuden a las víctimas en la estructuración de su caso, la compilación del material probatorio requerido para su postulación y la asesoría jurídica en cada caso en particular, para que logren la restitución de sus derechos, superen el temor de reclamarlos y se logre frenar la violación constante a los Derechos Humanos en el país.

Con el ánimo de atender a esta problemática el Estado colombiano decidió tomar la vía de la Teoría de la Justicia Transicional como una posibilidad a través de la cual se propone la transformación radical de un orden social y político que ha generado violaciones generalizadas y sistemáticas de Derechos Humanos para lograr la paz y la reconciliación, mediante un proceso de negociación entre el Estado y los grupos armados insurgentes que comprenda el "perdón" como una medida a través de la cual el actor causante del daño no sería acreedor de la totalidad del castigo retribuido por la pena recibida, mediante indultos, medidas de libertad provisional y disminución de la pena, etc. Mediante este proceso, el Estado debe garantizar los estándares mínimos de protección de Derechos Humanos relacionados con los principios de verdad, justicia, reparación y garantías de no repetición consagrados en los instrumentos internacionales. (Pérez Fuentes et ál., 2019, p. 171) 
El vincular a los estudiantes de último semestre a la JEP, con el propósito de contribuir las universidades a la restitución de los derechos de las víctimas del conflicto armado de escasos recursos, es una labor de importantísima justicia social, que haría una gran contribución a la consolidación de la paz y a la conformación de un nuevo escenario del país, en el que cada vez tenga menos uso la aplicación de la justicia propia como mecanismo para obtener la defensa de los derechos propios (Palomares y Calonje, 2015). No solo por los costos de un proceso judicial, sino también en la celeridad de estos, tanto las personas con menos recursos como los grupos marginados sienten que sus causas pasan al olvido por no tener ellos la vocería o cercanía suficiente a los círculos de poder. Además, la congestión judicial y la falta de personal y de recursos adecuados y suficientes para la rama judicial hacen que sean lentas las respuestas judiciales y que los procesos no avancen con la rapidez necesaria, convirtiéndose esa misma demora en un factor de impunidad, que en el contexto de la justicia transicional agrava la situación de las víctimas, especialmente para las que más requieren de una indemnización (Tremolada, 2014).

La barrera discriminatoria más difícil de superar no es la derivada de los costos de acceso, sino el de soportar la demora en la resolución de la controversia, que si bien, en virtud de las previsiones internacionales, debe ser dentro de un plazo razonable, en el país desborda la imaginación y permite que las partes más prósperas, entre ellas el Estado, jueguen y se aprovechen de ello. (Tremolada, 2014, p. 1)

Sin la restitución de las víctimas, la JEP se convierte en un sistema judicial privilegiado de legalización para los combatientes del conflicto armado, que carece de un impacto significativo para la consolidación de una nueva sociedad, y la paz se vuelve una realidad inalcanzable a nivel social. Hasta ahora, esa es la descripción que puede hacerse de lo logrado por la JEP, 
tanto por las demoras en los procesos de la jurisdicción especial como por el poco número de víctimas indemnizadas, que permite concluir que la tarea lograda hasta el momento ha sido deficiente, especialmente para las que tienen menos recursos económicos.

Uno de los mayores desafíos que Colombia enfrenta en la construcción de paz es la reparación de las víctimas de violaciones graves a los derechos humanos como consecuencia del conflicto armado, que todavía sigue activo después de 50 años. En el caso de las reparaciones el reto es, literalmente, enorme: según datos de la Unidad de Víctimas (el organismo institucional que gestiona los programas de reparación), actualmente hay más de siete millones de víctimas registradas en el país. Y las cifras siguen creciendo. (ICTJ, 2015, p. 1)

La propuesta de vincular los consultorios jurídicos a la atención de las víctimas del conflicto armado les permite a los estudiantes de derecho de últimos semestres tener la oportunidad de acercarse a los mecanismos propios de la JEP. Al mismo tiempo, permite conocer de primera mano los problemas que sufren las víctimas en el territorio nacional. Desde el campo de su formación jurídica, tal práctica amplía el conocimiento de la sociología jurídica nacional y de los grandes retos a los que deben enfrentarse en el ejercicio de su profesión. Esa práctica, además, hace posible que las universidades se comprometan con la consolidación de la paz y la construcción de un nuevo proyecto social más justo, así como que en la formación profesional de los abogados se apropien de las vivencias propias del litigio que no se abordan en los cursos ni talleres usuales de la vida universitaria actual (Quintero y Molina, 2013).

Los hechos que se abordan en la restitución de los derechos de las víctimas no solo deben centrarse en el estudio del conflicto y el campo penal, sino que requieren del conocimiento de derecho civil, administrativo y constitucional, ámbitos indispensables para que las nuevas generaciones 
de abogados estudien y conozcan cómo se han venido vinculando a la justicia restaurativa. Teniendo como marco máximo de acción la propuesta de vincular los consultorios jurídicos al SAAD, en función de que las universidades les permiten a las personas de escasos recursos la posibilidad de acceder al sistema judicial para que puedan hacer valer sus derechos. "La práctica de consultorio que se realiza los dos últimos años de la carrera de derecho, además de ser requisito para obtener su título, es la más clara materialización de la función social de la profesión de abogado" (Universidad Cooperativa de Colombia, s. f., p. 1). Hay que tener en cuenta que el SNDP es un "servicio público que organiza, dirige y controla el Defensor del Pueblo, a favor de las personas que lo requieren para asumir asistencia y representación judicial y garantizar el pleno e igual acceso a la administración de justicia en materia penal" (Defensoría del Pueblo, s. f., p. 1).

El objetivo principal de vincular los consultorios jurídicos al SAAD de la JEP es fortalecerlo con personal idóneo y gratuito, con el propósito de agilizar el proceso de recolección, sistematización y respuesta de los requerimientos de las víctimas del conflicto armado de escasos recursos, para lograr agilizar la restitución de sus derechos, lo que va más allá de la indemnización económica, lográndose así que la paz sea algo más que una promesa política.

La Ley de Víctimas y el discurso político hacen promesas difíciles de cumplir cuando aseguran que la reparación transformará vidas y será integral. No consideran los niveles de pobreza y marginalidad en que viven muchas víctimas, ni tampoco su desbordante número. Cuando dichas promesas son hechas por ley, la incapacidad de cumplirlas afecta seriamente a la credibilidad de la ley y la seguridad jurídica. Los compromisos legales que el Estado adquirió con la Ley de Víctimas no 
pueden ser exonerados posteriormente bajo argumentos de falta de capacidad o previsión por parte del propio Estado. (ICTJ, 2015, p. 1)

La metodología para que tal vinculación sea posible es la firma de un convenio entre la Defensoría del Pueblo y la JEP, así como de las universidades con facultades de derecho con la Defensoría del Pueblo, permitiendo que sus estudiantes realicen sus prácticas en la justicia restaurativa. A su vez, las universidades deben reacomodar los consultorios jurídicos para que en ellos puedan ser atendidas las víctimas del conflicto armado de escasos recursos. La mayor bondad de la propuesta es que se agilizaría la capacidad de respuesta del SAAD y, con ello, se aportaría desde las universidades en la consolidación de una paz estable y duradera en el país (Gallego, 2014). El otro beneficio es el fortalecimiento de la legitimidad de la justicia restaurativa en el país, toda vez que no es una práctica ajena a la vida jurídica, sino un tema que debe estudiarse, analizarse y abordarse desde las universidades.

El otro gran beneficio de esta propuesta es que les permite a la nuevas generaciones de abogados conocer sobre lo que fue el conflicto, la problemática jurídica que de ella se desprende en el país y cuáles son los retos que se deben enfrentar para la construcción de un nuevo panorama social. Los costos de la vinculación de los consultorios jurídicos de las universidades al SAAD son mínimos, ya que la mayoría de las universidades cuentan con la logística que se necesita para poder atender a las víctimas del conflicto armado. Quizás la única modificación requerida, es la vinculación de docentes expertos en Derechos Humanos y de Justicia Restaurativa (Palomares, 2015).

Aparentemente, la principal crítica a esta propuesta es que se vincularían las universidades al Proceso de Paz, en la medida en que trabajarían en el restablecimiento de las víctimas del conflicto armado. Esa crítica quizás no 
sería desde el campo académico, sino desde las posturas políticas opuestas al Proceso de Paz, que consideran que la JEP es una jurisdicción llamada al fracaso. Para tales posturas, el mejor argumento es que el Proceso de Paz ya hace parte de la sociedad colombiana y de su sistema jurídico, y la sociedad en general debe aprender a acatarlo independientemente de sus posturas políticas. La mayoría de las labores que tendrían que realizar los estudiantes de derecho de los consultorios jurídicos, según esta propuesta, estaría encaminada a la consolidación de la documentación requerida para la protección y restitución de derechos de las víctimas del conflicto armado de escasos recursos. Al parecer, tales tareas a primera vista parecen acciones propias de oficinistas, pero en realidad, para que se logren consolidar en debida forma, tales acciones exigen el conocimiento de la Constitución y de las leyes, que solo los estudiosos del derecho pueden hacer de manera competente, pertinente y apropiada (Rodríguez, 2014).

\section{Conclusiones}

Mientras no se logre la atención integral, rápida y eficaz de las víctimas del conflicto armado, el Proceso de Paz no logrará impactar la sociedad y fortalecer un nuevo proyecto social en Colombia, teniendo presente que las víctimas han sido comunidades enteras, forzadas a desplazarse tras haber sido algunos de sus miembros víctimas de graves crímenes por agentes que atentaron contra sus Derechos Humanos. Esta situación fue reiterativa en el país por décadas y no solo afectó su situación económica: “La afectación psicosocial, física, cultural y territorial que vivieron estas comunidades ha llegado a plantear en el proceso de una construcción de paz estable y duradera la importancia de reparaciones tanto individuales como colectivas" (Programa de las Naciones Unidas para el Desarrollo [PNUD], 2019, p. 1). 
En la actualidad, los consultorios jurídicos tienen una gran demanda por personas de escasos recursos que requieren una asesoría para un sinnúmero de asuntos jurídicos (Echeverry y Díaz, 2016). En la Ley 583 de 2000, en su artículo primero, se establece que los estudiantes que pertenezcan a ellos podrán litigar en causa ajena actuando como abogados de pobres en algunos procesos penales, como representantes de la parte civil, de oficio en los procesos penales como voceros o defensores en audiencia. También pueden actuar en procesos civiles que conocen los jueces municipales en única instancia al igual que en los procesos de alimentos que se adelanten ante los jueces de familia, así como de oficio en los procesos disciplinarios de competencia de las personerías municipales y la Procuraduría General de la Nación; en los procesos de responsabilidad fiscal de competencia de las contralorías municipales, distritales, departamentales y General de la República, y en los procesos administrativos de carácter sancionatorio que adelanten las autoridades administrativas, los organismos de control y las entidades constitucionales autónomas.

Cabe resaltar la condición que establece la Sentencia C-143 del 7 de febrero de 2001: "siempre que los estudiantes que actúen en su desarrollo ejerzan el Derecho bajo la supervisión, la guía y el control de las instituciones educativas a las cuales pertenecen", ya que responde también a que, en un sinnúmero de ocasiones, los procesados alegan nulidades debidas a la inexperiencia de los estudiantes del consultorio jurídico cuando los resultados no son de su agrado. Esto da como resultado un desgaste de la administración de justicia, al operarse en ella unas audiencias que pueden estar viciadas por desconocimiento del derecho de defensa de los procesados, situación que no sería posible en la propuesta expuesta en este trabajo, en la que los estudiantes, aunque no participarían como defensores, sí contribuirían en la defensa de los derechos de las víctimas. 
Las universidades del país están llamadas a jugar un papel protagónico en el posconflicto colombiano, buscando liderar procesos de reincorporación social y reconstrucción de la sociedad, en los que sea posible pensar en procedimientos alternos a la violencia para resolver las controversias sociales. En ese sentido, las facultades de derecho, al atender a las víctimas del conflicto armado, estarían contribuyendo de manera efectiva en la búsqueda de la paz.

Los consultorios jurídicos pueden desempeñar un papel muy importante de asesoría a las víctimas frente a todos sus derechos y la manera de reclamarlos ante las autoridades correspondientes, si trabajan de la mano con los servicios que ofrecen las Defensoría del Pueblo y la Procuraduría General de la Nación; de este modo, colaboran con la descongestión judicial al aportar en el trabajo de campo de los abogados defensores públicos de las víctimas.

\section{Referencias}

Aguirre, A. J. (2019). Victimario: la víctima desconocida del conflicto armado colombiano. Análisis de su reparación en torno al principio de igualdad. Revista Derecho del Estado, 43, 291-320. https://doi.org/10.18601/01229893.n43.11

Álvarez, E. (2017, 16 de enero). El crimen organizado en lo local: ¿̇un problema subvalorado en Colombia? FIP, Fundación Ideas para la Paz. http://www.ideaspaz.org/publications/posts/1449

Álvarez, E., Cajiao, A. y Pardo, D. (2018, 10 de abril). Las disidencias de las FARC: un problema en auge. FIP, Fundación Ideas para la Paz.

http://www.ideaspaz.org/publications/posts/1662

Arboleda, A. (2017, 15 de noviembre). ¿Cuál es el nuevo rol del abogado y las firmas en la construcción de la paz? Legis, Ámbito Jurídico. https://www.ambitojuridico.com/noticias/general/constitucional-y-derechoshumanos/cual-es-el-nuevo-rol-del-abogado-y-las-firmas-en

Revista IUSTA

ISSN: 1900-0448 | e-ISSN: 2500-5286 | DOI: https://doi.org/10.15332/25005286

N. 054 | enero-junio de 2021 
Bonilla, G., Rodríguez, D. y Cardona, R. (2016). Ciudadanías emergentes: a propósito del posconflicto y la urgencia de una pedagogía para la paz desde la polifacética condición humana. Espiral, Revista de Docencia e Investigación, 6(2), 37-52. https://doi.org/10.15332/erdi.v6i2.1648

Castellanos, A. (2018). El Estado colombiano frente a la reparación de víctimas del conflicto armado: examen legal de la figura de reparación integral para su implementación [tesis para optar al grado de Maestría en Derecho Público]. Repositorio Institucional de la Universidad Santo Tomás. https://repository.usta.edu.co/bitstream/handle/11634/10672/Castellanosandrea 2018.pdf? sequence $=1 \&$ isAllowed $=\mathrm{y}$

Centro Internacional para la Justicia Transicional. (2015, 6 de abril). La reparación de las víctimas en Colombia, una promesa parcialmente cumplida. https://www.ictj.org/es/news/estudio-reparacion-individual-victimas-colombia

Centro Internacional para la Justicia Transicional. (2009) ¿Qué es la justicia transicional? https://www.ictj.org/sites/default/files/ICTJ-Global-TransitionalJustice-2009-Spanish.pdf

Colombia. Acto Legislativo o1 de 2017. Por medio del cual se crea un título de disposiciones transitorias de la Constitución para la terminación del conflicto armado y la construcción de una paz estable y duradera y se dictan otras disposiciones. Abril 4 de 2017. DO núm. 50196.

Colombia. Acuerdo Final para la terminación del conflicto y la construcción de una paz estable y duradera. Gobierno Naciona de Colombia - Fuerzas Armadas Revolucionarias de Colombia- Ejército del Pueblo. Agosto 24 de 2016. http://www.realinstitutoelcano.org/wps/wcm/connect/f272865f-5a3a-44e6-84f5b21eff53b424/Acuerdo-final-pazColombia.pdf?MOD=AJPERES\&CACHEID=f272865f-5a3a-44e6-84f5$\underline{\mathrm{b} 21 \mathrm{eff} 53 \mathrm{~b} 424}$

Colombia. Decreto 196 de 1971. Por el cual se dicta el estatuto del ejercicio de la abogacía. Febrero 12 de1971. DO núm. 33255 https://www.ramajudicial.gov.co/documents/10228/2045453/DECRETO+196+D E+1971+PDF.pdf/15a9ad5b-bd77-46dc-b957-5c75861744f5?version=1.2 
Colombia. Decreto 1166 de 2018. Por el cual se adiciona un capítulo al Título 5 de la Parte 2 del Libro 2 del Decreto 1069 de 2015, por el cual se expide el Decreto Reglamentario Único del Sector Justicia y del Derecho, y se reglamenta el Sistema Autónomo de Asesoría y Defensa que se ofrecerá respecto a los trámites y actuaciones previstas en la Ley 1820 de 2016, ante el Sistema Integral de Verdad, Justicia, Reparación y No Repetición -SIVJRNR. Julio 11 de 2018.

https://dapre.presidencia.gov.co/normativa/normativa/DECRETO\%201166\%20D EL\%2011\%20DE\%20JULIO\%20DE\%202018.pdf

Colombia. Ley 583 de 2000. Por la cual se modifican los artículos 30 y 9 del Decreto 196 de 1971. Junio 12 de 2000. DO núm. 44042 http://www.secretariasenado.gov.co/senado/basedoc/ley 0583_2000.html

Colombia. Ley 1448 de 2011. Por la cual se dictan medidas de atención, asistencia y reparación integral a las víctimas del conflicto armado interno y se dictan otras disposiciones. junio 10 de 2011. DO núm. 48096. http://www.suinjuriscol.gov.co/viewDocument.asp? ruta=Leyes $/ 1680697$

Colombia. Ley 1957 de 2019. Estatutaria de la Administración de Justicia en la Jurisdicción Especial para la Paz. Junio 6 de 2019. DO núm. 50976. http://www.secretariasenado.gov.co/senado/basedoc/ley_1957_2019.html

"Corte Constitucional amplió la vigencia de la Ley de Víctimas". (2019, 5 de diciembre). El Espectador. https://www.elespectador.com/noticias/judicial/corte-constitucionalamplio-la-vigencia-de-la-ley-de-victimas-articulo-894429

Corte Constitucional de Colombia [CC], febrero 7, 2001, MP: J. G. Hernández Galindo, Sentencia C-143/o1, [Colom.].

Corte Constitucional de Colombia [CC], marzo 29, 2012, MP: G. Mendoza, Sentencia C253A/12, [Colom.]. https://www.corteconstitucional.gov.co/relatoria/2012/C253A-12.htm\#: :text=Por\%2ola\%20cual\%20se\%2odictan,V\%C3\%8DCTIMAS

Corte Constitucional de Colombia [CC], mayo 15, 2013, MP: N. Pinilla Pinilla, Sentencia C-28o/13, [Colom.]. https://www.corteconstitucional.gov.co/relatoria/2013/C280-13.htm

Corte Constitucional de Colombia [CC], noviembre 11, 2014, MP: J. I. Palacio Palacio, Sentencia T-834/14, [Colom.].

https://www.corteconstitucional.gov.co/relatoria/2014/t-834-14.htm 
Corte Constitucional de Colombia [CC], Diciembre 5, 2019, MP: J. F. Reyes Cuartas, Sentencia C-588/19, [Colom.].

https://www.corteconstitucional.gov.co/relatoria/2019/C-588-19.htm

“Corte ordena reparar a las víctimas de las Bacrim”. (2015, marzo 25). Corte ordena reparar a las víctimas de las Bacrim. Semana.

https://www.semana.com/nacion/articulo/corte-constitucional-ordena-repararvictimas-de-las-Bacrim/422187-3

Defensoría del Pueblo. (2021). Sistema Nacional de Defensoría Pública (SNDP). https://www.defensoria.gov.co/es/public/atencionciudadanoa/1477/SistemaNacional-de-Defensor\%C3\%ADa-P\%C3\%BAblica(SNDP).htm\#: :text=Es\%20un\%20servicio\%20p\%C3\%BAblico\%2oque,de\%2ojust icia\%20en\%20materia\%2openal

Echeverry Osorio, D. L. y Díaz Ricardo, S. (2016). Minería aurífera ilegal en el resguardo indígena alto Andágueda. Novum Jus, 10(1), 135-149. https://doi.org/10.14718/NovumJus.2016.10.1.6

Galán Galindo, A. R. (2017). Entre justicia y moralidad: criterios metateóricos en cuanto a la justicia la moral y el derecho. Novum Jus, 10(2), 103-118. https://doi.org/10.14718/NovumJus.2016.10.2.6

Gallego, J. (2014) Paradoja y complejidad de los derechos humanos en la sociedad moderna. Sentido y comunicación. Revista IUSTA, 1(40), 143-165. https://doi.org/10.15332/s1900-0448.2014.0040.01

Guarín, E. y Aldana, J. (2016). Los límites de la teoría del equilibrio como alternativa de solución a la cuestión de la prevalencia del poder del Alto Tribunal de lo Constitucional en Colombia. Via Inveniendi Et Iudicandi, 11(1), 59-82. https://doi.org/10.15332/s1909-0528.2016.0001.01

"Hay más de 2.400 grupos armados y de delincuencia organizada en Colombia". (2019, febrero 7). BLU Radio. https://www.bluradio.com/nacion/hay-mas-de-2400grupos-armados-y-de-delincuencia-organizada-en-colombia-205207-ie430/

Humbarita, J. (2015). Derecho Constitucional Hispanoamericano frente a la realidad institucional, manifiesta divergencia. Revista IUSTA, 2(43).

https://doi.org/10.15332/s1900-0448.2015.0043.03

Revista IUSTA

ISSN: 1900-0448 | e-ISSN: 2500-5286 | DOI: https://doi.org/10.15332/25005286

N. 054 | enero-junio de 2021 
"Indemnizar a todas las víctimas cuesta 45 billones de pesos". (8 de marzo de 2020). $E l$

Tiempo. https://www.eltiempo.com/politica/proceso-de-paz/director-de-unidadde-victimas-dice-que-indemnizarlas-a-todas-cuesta-45-billones-470400

Jurisdicción Especial para la Paz (JEP). (2019, julio 2). Así funciona el Sistema Autónomo de Asesoría y Defensa (SAAD) de la JEP. https://www.jep.gov.co/Salade-Prensa/Paginas/Estas-son-las-funciones-del-Sistema-Aut\%C3\%B3nomo-deAsesor\%C3\%ADa-y-Defensa-de-la-JEP.aspx

Kapkin, S. (2017, enero 11). 'La Oficina de Envigado y los Gaitanistas tienen 13.500 miembros en Antioquia': Corpades. Pacifista. https://pacifista.tv/notas/la-oficinade-envigado-y-los-gaitanistas-tienen-13-500-miembros-en-antioquia-corpades/

Leyke, S., Ospina, J.C. y Linares, C. (2018). Guía 02: La satisfacción de los derechos de las víctimas: el reto de la JEP y sus comparecientes. Comisión Colombiana de Juristas.

López, N. (2015). Las Bacrim: ċactores del conflicto armado colombiano? Revista de Derecho Público, 34, 1-29. http://dx.doi.org/10.15425/redepub.34.2015.11

"Lo que trae la Ley Estatutaria de la JEP que sancionó Duque”. (2019, junio 7). Legis Ámbito Jurídico. https://www.ambitojuridico.com/noticias/penal/penal/lo-quetrae-la-ley-estatutaria-de-la-jep-que-sanciono-duque

Martínez, C. (2018). La reparación integral a las víctimas del conflicto armado en Colombia en el marco de la justicia transicional [tesis para optar al Doctorado en Gobierno y Administración Pública, Universidad Complutense de Madrid]. EPrints Complutense. https://eprints.ucm.es/49477/1/T40329.pdf

Morales Ferrer, S. y Daza Coronado, S. (2016). El deber de información al paciente, el consentimiento informado y el tratamiento ambulatorio en España. Novum Jus, 1O(2), 11-34. https://doi.org/10.14718/NovumJus.2016.10.2.1

Pacheco, S. (2019, noviembre 24). ¿Cómo los llamamos: paramilitares, disidencias, grupos residuales, terroristas? El Espectador.

https://www.elespectador.com/colombia2020/opinion/como-los-llamamosparamilitares-disidencias-grupos-residuales-terroristas-columna-892676

Palomares, J. (2015). El carácter vinculante de la jurisprudencia constitucional en el derecho alemán. Revista Via Inveniendi et Iudicandi, 1O(2), 29-56. https://doi.org/10.15332/s1909-0528.2015.0002.06

Revista IUSTA

ISSN: 1900-0448 | e-ISSN: 2500-5286 | DOI: https://doi.org/10.15332/25005286

N. 054 | enero-junio de 2021 
Palomares, J. y Calonje, N. (2015). Tratados de libre comercio Colombia-Asia: Cuestión preliminar y perfiles de negociación en Revista IUSTA, 2(43), 17-41.

https://doi.org/10.15332/s1900-0448.2015.0043.06

Pares, Fundación Paz y Reconciliación. (2019, agosto 28). Más sombras que luces. La seguridad en Colombia a un año del gobierno de Iván Duque. 2019.

https://pares.com.co/wp-content/uploads/2019/o8/Que\%CC\%81-paso\%CC\%81con-la-seguridad-a-un-an\%CC\%830-de-Duque-final- compressed-Final.pdf

Pérez Fuentes, C., Arenas Jaimes, P., Vega Ardila, L. y Camacho Castilla, J. (2019). Análisis jurisprudencial de las garantías de los derechos de las víctimas del conflicto armado por bandas criminales en Colombia. Revista Estudios SocioJurídicos, 21(2), 167-196. https://doi.org/10.12804/revistas.urosario.edu.co/sociojuridicos/a.7431

Programa de las Naciones Unidas para el Desarrollo (PNUD). (2019). La reparación de las víctimas es nuestro compromiso. https://www.co.undp.org/content/colombia/es/home/presscenter/articles/2019/1 1/la-reparacion-de-las-victimas-es-nuestro-compromiso.html

Quintero, S. y Molina, D. (2013). La Ilegalidad: una herramienta de análisis para la naturaleza del conflicto en Colombia. Revista Via Inveniendi et Iudicandi, 8(1), 159-190. https://doi.org/10.15332/s1909-0528.2013.0001.06

Recalde, G., Blanco, T. y Bonilla, D. (2017). Justicia de pobres: Una genealogía de los consultorios jurídicos en Colombia. Revista de Derecho, 47, 1-72. http://dx.doi.org/10.14482/dere.47.9772

Red Nacional de Información (RNI). (2020). Víctimas registradas. Fecha de corte: 01 ene. 2020. https://cifras.unidadvictimas.gov.co/

Rodríguez, A. (2014). Indicadores de constitucionalidad de las políticas públicas: enfoque de gestión de derechos. Revista Via Inveniendi et Iudicandi, 9(2), 135-175. https://doi.org/10.15332/s1909-0528.2014.0002.06

“Solo el 2\% de las víctimas del conflicto han obtenido reparación”. (2020, octubre 7). Vanguardia. https://www.vanguardia.com/colombia/solo-el-2-de-las-victimasdel-conflicto-han-obtenido-reparacion-DM2970050

Revista IUSTA

ISSN: 1900-0448 | e-ISSN: 2500-5286 | DOI: https://doi.org/10.15332/25005286

N. ${ }^{\circ} 54$ | enero-junio de 2021 
Tremolada, E. (2014, mayo 5). ¿El acceso a la justicia, una utopía en Colombia? La República. https://www.larepublica.co/analisis/eric-tremolada-506119/el-accesoa-la-justicia-una-utopia-en-colombia-2118026

Universidad Cooperativa de Colombia. (s. f.). Asuntos en los cuales los estudiantes de consultorio jurídico están facultados para actuar ante juzgados.

https://www.ucc.edu.co/ibague/Documents/aa\%20aASUNTOS\%20EN\%20LOS\% 2OCUALES\%2OLOS\%20ESTUDIANTES\%20DE\%20CONSULTORIO\%2OJUR\%C3 \%8DDICO\%20ESTAN\%20FACULTADOS\%20PARA\%20ACTUAR\%20ANTE\%20J UZGADOS.pdf

Verdadabierta.com. (2015, abril 19). Tres problemas que desvelan a las víctimas. https://verdadabierta.com/tres-problemas-que-desvelan-a-las-victimas/ 